\title{
Effects of isoflurane post-conditioning on myocardial connexin 43 expression in rats
}

Ivan Agnić ${ }^{1}$, Natalija Filipović ${ }^{2}$, Katarina Vukojević ${ }^{2}$, Mirna Saraga-Babić ${ }^{2}$ and Ivica Grković ${ }^{2}$

${ }^{1}$ Department of Anesthesiology, University Hospital Split, Split, Croatia

${ }^{2}$ Department of Anatomy, Histology and Embryology, University of Split School of Medicine, Split, Croatia
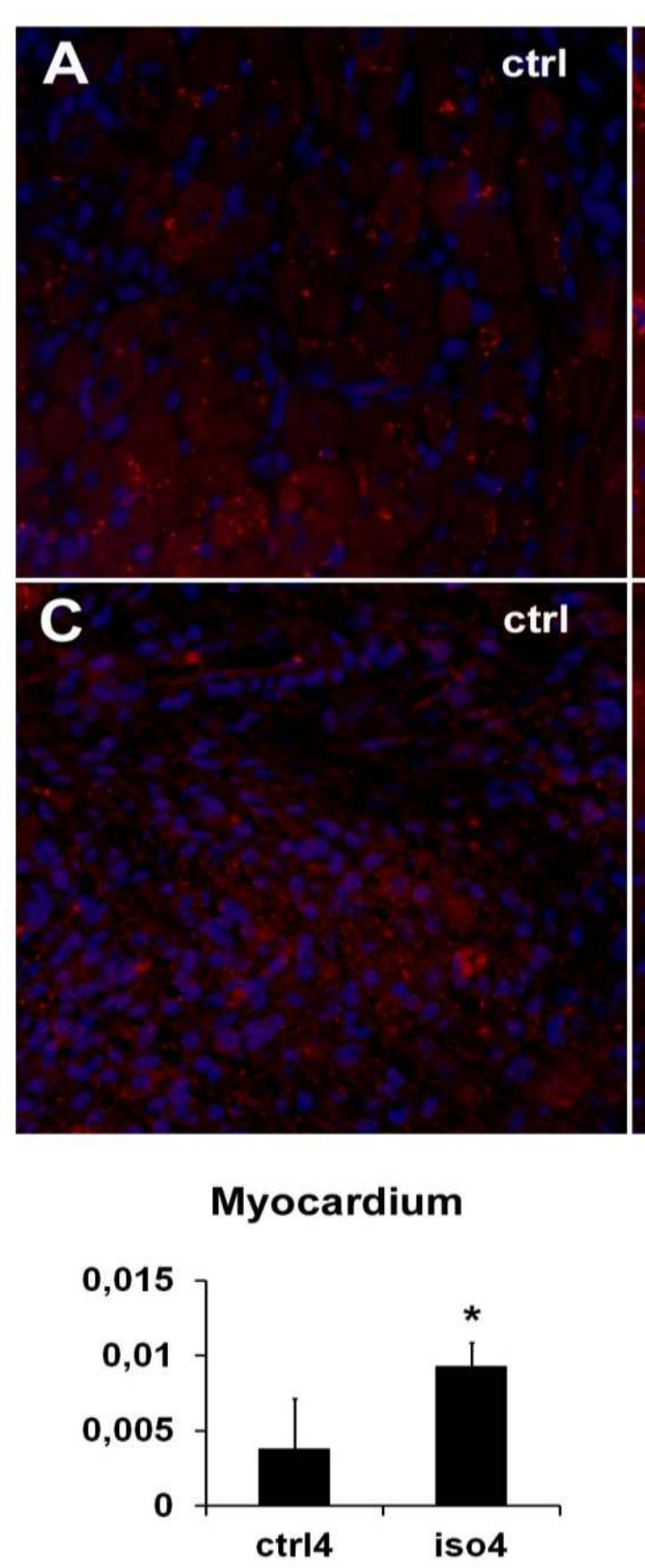

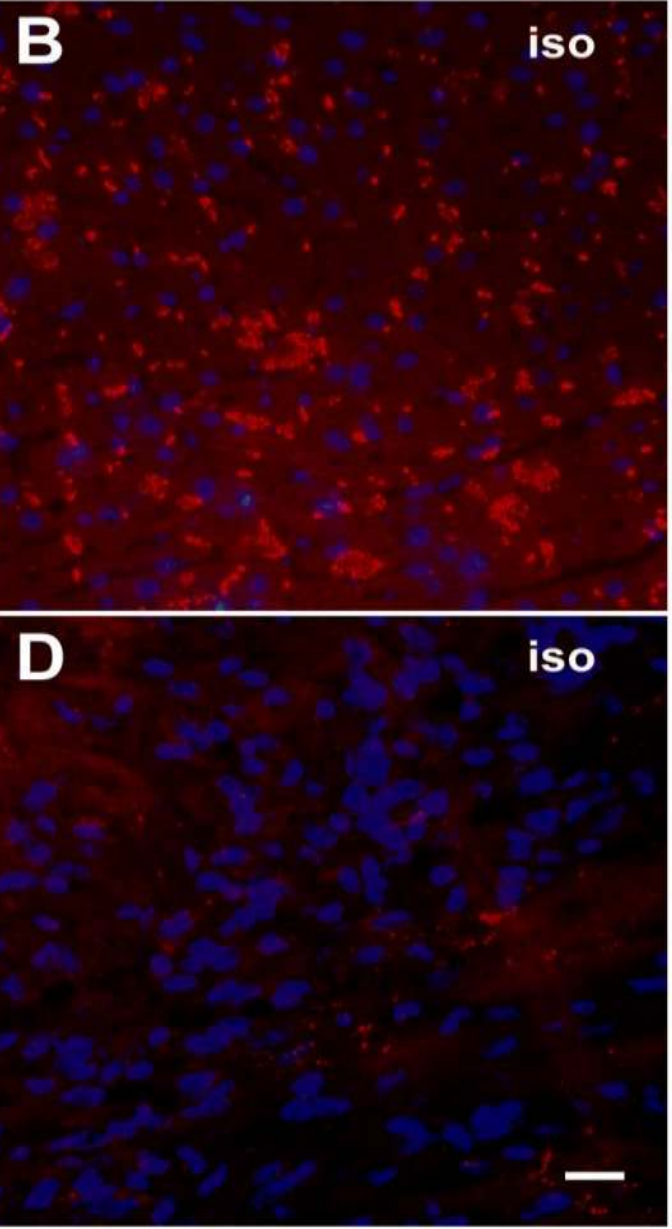

Granulation tissue

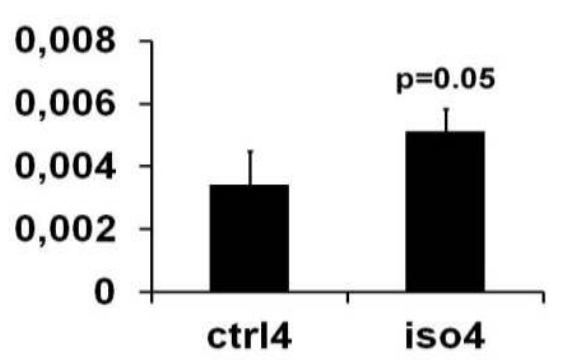

Background and Goal of Study: Connexin $43(\mathrm{Cx} 43)$ is a gap junction protein located mainly in the ventricular myocardium which plays an important role in intercellular electrical conduction. Studies have shown that volatile anesthetic postconditioning reduce the incidence of ventricular arrhythmias. Therefore, the aim of this study was to investigate weather isoflurane post-conditioning has the effect on the connexin 43 expression in ventricular myocardium and infarct zone.

Materials and methods: Ischemia was induced in SpragueDawley female rats for 30 minutes. Starting from the last 5 minutes of ischemia up until 10 minutes into reperfusion time, the isoflurane group $(n=8)$ recieved 1 MAC of isoflurane, while the control group $(n=8)$ received only an air/oxygen mixture. The animals were left to survive 4 days (subacute phase) or 14 days after reperfusion (chronic phase of infarct healing). Colocalization of Nestin and Cx43 antibodies was used as a marker of "de novo" formed myoblasts from progenitor cells. For statistical comparison between groups we used t-test.

Results and discussion: In subacute phase of infarct healing the percentage (mean $\pm \mathrm{SD}$ ) of $\mathrm{Cx} 43$ expression in myocardium was significantly higher in isoflurane treated animals $(0.0093 \pm 0.0016 \%)$ in comparison to the control group $(0.0038 \pm 0.0034 \%), \mathrm{p}=0.042$. However, when comparison of infarct zone was done $\mathrm{p}$ was $0.050(0.0051 \pm$ 0.00074 vs. $0.0034 \pm 0.0011 \%$ ).
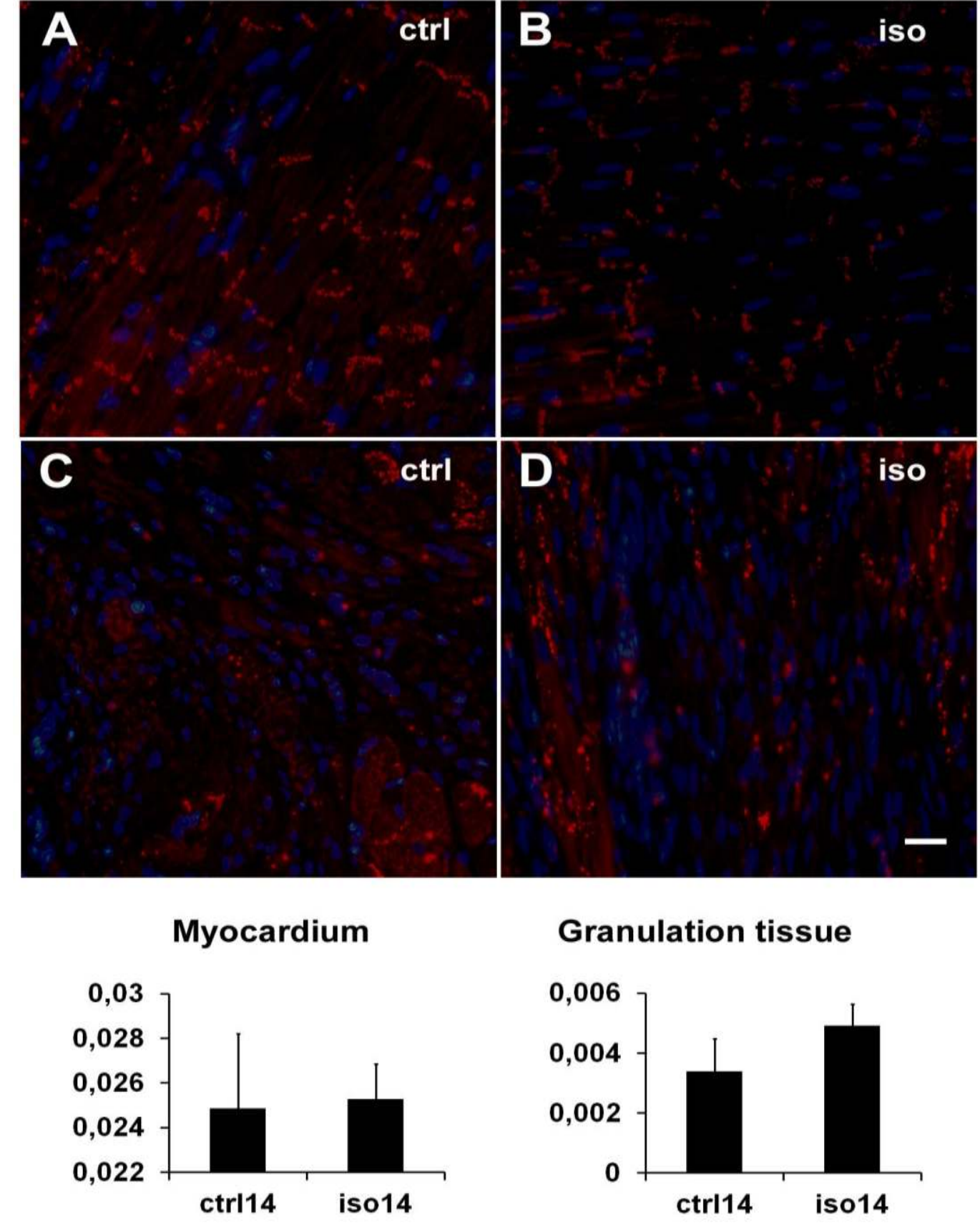

In the chronic phase of infarct healing, the $\mathrm{Cx} 43$ expression in myocardium ( $\mathrm{p}=0.987 ; 0.025 \pm 0.034$ vs. $0.025 \pm 0.035 \%)$ and infarct zone $(\mathrm{p}=0.104 ; 0.0049 \pm 0.0013$ vs. $0.0034 \pm$ $0.00074 \%$ ) was not significantly different between isoflurane post-conditioned vs. control groups, respectively. Colocalization of Nestin and Cx43 was observed in newly formed myocytes, indicating their connection with existing mature myocytes.

Conclusion: Isoflurane treated animals had an early phase augmentation of $\mathrm{Cx} 43$ expression in myocardium.
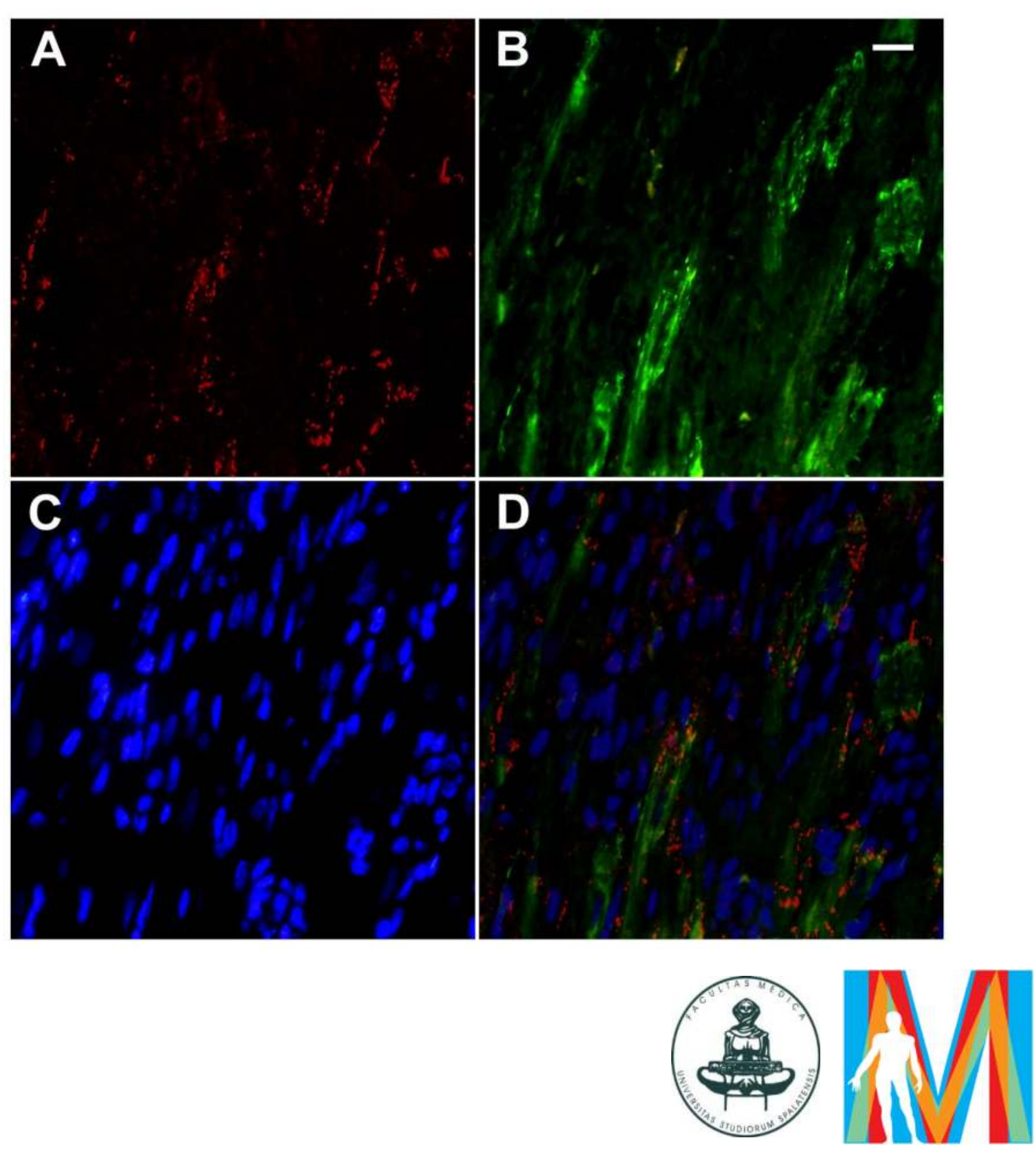